\title{
SHALLOW BATHYMETRY ESTIMATION BASED ON LANDSAT 8 REMOTELY SENSED DATA AT BOHAI SEA
}

\author{
Dianjun Zhang ${ }^{1}$, Jie Zhan', Chenxu Wang ${ }^{1}$, Guoqing Zhou ${ }^{2 *}$ \\ 1 School of Marine Science and Technology, Tianjin University, Tianjin 300072, China; zhangdianjun123@163.com; \\ 2 Guangxi Key Laboratory for Spatial Information and Geomatics, Guilin University of Technology, Guilin, 541004, P. R. China; \\ gzhou@glut.edu.cn
}

KEY WORDS: Landsat 8 OLI; Bohai; remote sensing image; shallow bathymetry

\begin{abstract}
Bathymetry is a key variable in ocean monitoring and measurement research. It becomes more and more important for development of rapid method to invert shallow sea water depth. In this study, a water depth inversion method based on multi-band model is established to analyze the relationship between different bands of Landsat 8 OLI multi-spectral and measured data. The average absolute error of the model is $1.48 \mathrm{~m}$ at $10-20 \mathrm{~m}$ water depth and the average relative error is $13.12 \%$. The water depth inversion accuracy under normal conditions are achieved, indicating that the model will have a promising practical application in the future.
\end{abstract}

\section{INTRODUCTION}

As an important indicator of ocean measurement, water depth is also a topographical factor that cannot be ignored in shallow waters[1-3]. It has a non-negligible effect on island coastal zone management and development, maritime shipping and transportation, and marine engineering projects. Water depth measurement is one of the most basic tasks in marine topographic survey, and it is also one of the important contents of docks, ports, anchorage construction and navigation channels.

The estimation methods can be divided into active and passive remote sensing methods[4][5]. According to the characteristics of water depth inversion, it can be divided into hyper-spectral remote sensing water depth inversion, Lidar sounding and shallow seawater deep fusion detection. The most advantage of active remote sensing methods is the high accuracy of the obtained data. However, it is extremely expensive and labor-waste. Compared with active remote sensing, passive methods can achieve measurements in a variety of sea areas with fast speed and large area. The only drawback is that the accuracy is not so high for those cases where the accuracy requirements are very strict.

\section{METHOD}

The functional model of the measured water depth data and the reflectance of 11 different bands in the
Landsat 8 OLI image is investigated, and the reflectance of the 9 bands and the actual water depth data are respectively plotted. The scatter plot of the point and the curve are fitted to select the band with the largest correlation coefficient, namely the blue-green band and the third band, to explore the basic form of the inversion model. According to the physical and optical properties of the ocean, we can find that among the 11 bands of the Landsat 8 OLI remote sensing image, the correlation coefficient between the third band and the measured water depth data is the highest. So the logarithm of the measured depth data and the reflectance of the third band is established. By fitting, it can be clearly found that the statistical model of the water depth inversion in the Bohai Sea is an exponential function as follows:

$$
\begin{gathered}
\mathrm{Z}=\exp ^{a_{1} X_{1}+a_{2} X_{2}+\cdots+a_{n} X_{n}+b} \\
\mathrm{X}_{\mathrm{i}}=\ln \left(L_{i}\right)
\end{gathered}
$$

Where $\mathrm{Z}$ is the measured water depth data; $\mathrm{X}_{\mathrm{i}}$ is the reflectivity of the i-band. 


\section{STUDY AND DATA}

\subsection{Study area}

The Bohai Sea is an inland sea. Compared with the Yellow Sea, the East China Sea and the South China Sea, it has many shallow sea areas. Its latitude is $37^{\circ} 07^{\prime} \sim 41^{\circ} 0$ N, and the longitude is $117^{\circ} 35^{\prime} \sim$ $121^{\circ} 10^{\prime} \mathrm{E}$ (Figure 1 ). The coast is inclined to the center and the strait, the

terrain is monotonous and gentle. And the water depth in the shallow waters is obviously different. Therefore, it is suitable to select the Bohai Sea as a study area for shallow seawater depth inversion research.

\subsection{Data}

The remote sensing images used in this study are Landsat 8 OLI multispectral data with orbit numbers $120 / 32,120 / 33,120 / 34,121 / 32,121 / 33,121 / 34$, and the image date is August 26, 2016. The obtained time was 02:35:03 (GMT). The solar elevation angle was $41.37672^{\circ}$ and the azimuth was $119.905227^{\circ}$.

The water depth measurement was carried out using the light buoy. The instrument was TYH-100C Xingang No. 40 light float. The light quality is twin flash (2) red 6 seconds with working frequency of 200 kHz. It was carried out in Tianjin Port main channel. The sounding range spans $0.3 \sim 120 \mathrm{~m}$ and the sounding accuracy is approximately $\pm 1 \mathrm{~cm} \pm 0.1 \% \mathrm{D}$ (D is water depth, in meters). The total sounding points are 65535 and the depth of the sounding point is mostly between $3 \mathrm{~m}$ and $65 \mathrm{~m}$.

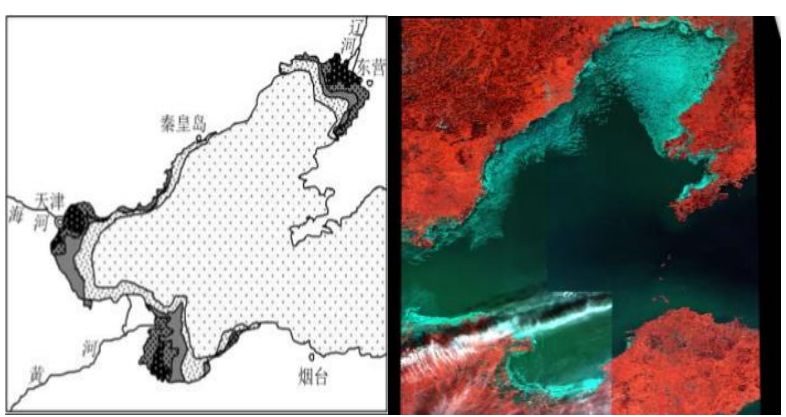

Figure 1. The study area of Bohai Sea

4.RESULTS AND DISCUSSION

\subsection{Determination of the bathymetry estimation} algorithm

The reflectance of the measured water depth data in each band was extracted using the ENVI software. The in situ water depth point were used to establish the index model with the reflectance data. Then, the formula is mathematically transformed into the regression equation through a large number of $\mathrm{Z}$ and the actual sampling points of the Bohai Sea, the model coefficients $a_{1}, a_{2}, a_{3}, a_{4}, a_{5}, a_{6}, a_{7}, a_{8}, a_{9}$ in the formula were obtained.

$$
\ln (Z)=a_{1} X_{1}+\cdots+a_{n} X_{n}+b
$$

The model optimization was carried out for the multi-band water depth model, which can be used to test the significance of the above-mentioned multiple regression equations. If the value of the model coefficient is $<0.5$, we can use the saliency $\mathrm{T}$ test models to obtain the model coefficients as follows.

$$
\begin{gathered}
a=33.9408 a_{1}+144.547 a_{2}+51.7024 a_{3}-50.844 a_{4}-76.977 \\
a_{5}+158.963 a_{6}-168.62 a_{7}-22.8 \\
416 a_{8}-931.12 a_{9}+6851.1
\end{gathered}
$$$$
\mathrm{Z}=\exp (a)
$$

Table 1. Evaluation results of the samples

\begin{tabular}{|c|c|c|c|}
\hline Depth & Numbers & Average absolute error & Average relative error \\
\hline$<1 \mathrm{~m}$ & 10 & $1.03 \mathrm{~m}$ & $9.43 \%$ \\
\hline $1-10 \mathrm{~m}$ & 50 & $1.52 \mathrm{~m}$ & $13.56 \%$ \\
\hline $10-20 \mathrm{~m}$ & 40 & $1.68 \mathrm{~m}$ & $12.89 \%$ \\
\hline Total & 100 & $1.48 \mathrm{~m}$ & $13.12 \%$ \\
\hline
\end{tabular}




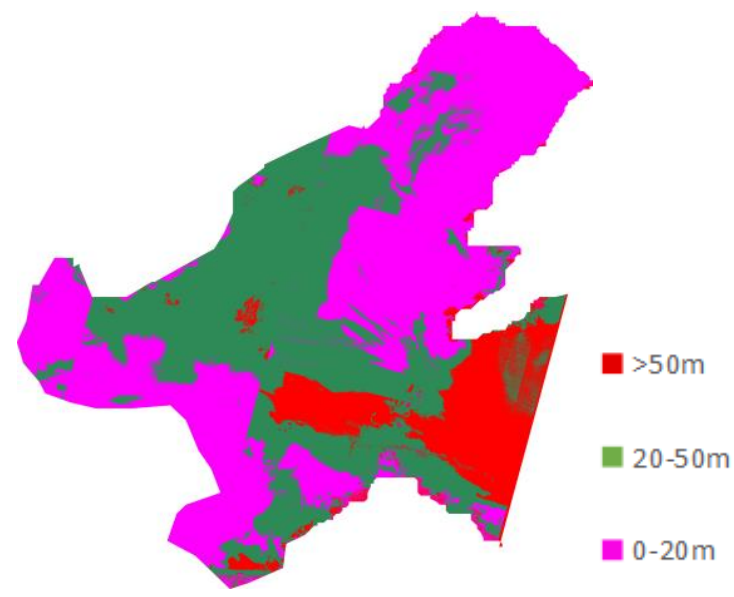

Figure 2 .Bathymetry estimation results from Landsat 8 data

\subsection{Discussion}

The estimation results are influenced by many aspects. These factors should be considered as following:

(1) The measured water depth data. The human activities in the shallow seas of the Bohai Sea are relatively frequent. The discharge of human pollutants, the dumping of marine debris, and the discharge of sewage from chemical parks have caused the rapid change for shallow water depth of Bohai Sea.

(2) The optical characteristics of the Bohai Sea itself. Bohai's own marine optical characteristics are not only related to its internal properties, but also affected by the discharge of pollutants from the chemical parks and ships in the ports around the Bohai Sea. Excess organic matter will cause a large number of phytoplankton to rapidly multiply, produce excessive suspended matter and unknown colored substances, which will cause remote sensing inversion of water depth.

(3) Omissions in the data preprocessing process. Coupled with the impact of atmospheric suspended matter on the blue-green band, the corrections have not been completely resolved, reducing the practical significance of our calibration process by more than half. As can be seen from the figure, the green part of the coastal zone cannot reflect the actual water depth due to the atmospheric correction influence.

\section{CONCLUSION}

In this paper, the Landsat 8 OLI multi-spectral image released by NASA is used to estimate the bathymetry in the Bohai shallow sea based on the multi-band statistical model. The average absolute error of the model in the water depth of $10-20 \mathrm{~m}$ is 1.48 $\mathrm{m}$. The average relative error is $13.12 \%$. It should be emphasized that the the model may have a promising application in the next work.

\section{ACKNOWLEDGMENTS}

This paper is financially supported by National Key R\&D Program of China (2018YFC1407400), 2016 Postdoctoral Fund 2016M592886XB and Guangxi Key Laboratory of Spatial Information and Geomatics $15-140-07-15$

\section{REFRENCES}

[1] Guo, X. et al. "Shallow water depth estimation based on OLI multi-spectral remote sensing images." Hydrographic Surveying and Charting. 2017, 37(06):54-57.

[2] Ma, Y. et al. "Advances in shallow water depth estimation from optical remote sensing ." Advances in Marine Science. 2018. 36(03):331-351.

[3] Liang, J. et al. "A spatial resolution effect analysis of remote sensing bathymetry." Acta Oceanologica Sinica. 2017(07).

[4] Wang, J. et al. "Water depth inversion from multi-spectral remote sensing in coral reef area." Remote Sensing Technology and Application. 2018. 33(01):61-67.

[5] Lyzenga, R. et al. "Multispectral bathymetry using a simple physically based algorithm." IEEE Transactions on Geoscience and Remote Sensing. 2006. 44(8): 2251-22. 